\title{
A (I)LEGITIMIDADE ATIVA DO MINISTÉRIO PÚBLICO NA AÇÃO CIVIL EX DELICTO
}

Rodolfo Centeio Figueiredo, Eduardo Buzetti Eustachio Bezerro

Universidade do Oeste Paulista - UNOESTE, curso de Direito, Presidente Prudente, SP. E-mail: rodolfocenteio@hotmail.com

\section{RESUMO}

Ilícitos penais geram consequências em nosso ordenamento jurídico que podem ultrapassar a esfera penal ensejando a possibilidade de reparação dos prejuízos sofridos pela vítima na esfera cível. É a chamada ação civil ex delicto. Nosso Código de Processo Penal em seu art. 68 estabelece que, quando o titular do direito à reparação do dano for pobre, compete ao Ministério Público a execução da sentença condenatória ou a ação civil. Entretanto, com o advento da Defensoria Pública na Constituição Federal de 1988, incumbindo-lhe a função de orientação jurídica e a defesa dos necessitados, passou-se a questionar a legitimidade do parquet. Concluímos que, manteve-se a legitimidade extraordinária do Ministério Público posto tratar-se de uma progressiva inconstitucionalidade do artigo em comento.

Palavras-chave: ação civil ex delicto, legitimidade, Ministério Público, vítima pobre, Defensoria Pública.

\section{THE ACTIVE (IL)LEGITIMACY OF THE PROSECUTION SERVICE IN THE CIVIL ACTION EX DELICTO}

\begin{abstract}
Criminal offenses generate consequences in our legal system that can overcome the criminal sphere opening the possibility of compensation for the damage suffered by the victim in the civil sphere. It is the civil action called ex delicto. Our Code of Criminal Procedure in its article 68 states that, when the person entitled to compensation for damage is poor, it is to Prosecution Service the execution of the condemnatory sentence or civil action. However, with the advent of the Public Defender in the Federal Constitution of 1988, instructing his legal guidance function and the defense of the needy began to question the legitimacy of the parquet. We conclude that, remained the extraordinary legitimacy of the Prosecution Service considering that this is a progressive unconstitutionality of article under discussion.

Keywords: civil action ex delicto, legitimacy, Prosecution Service, poor victim, Public Defender.
\end{abstract}




\section{INTRODUÇÃo}

Não se pode imaginar que a ocorrência de uma infração penal traga consequências apenas e tão somente na área penal. Muitas vezes, o fato que a lei tipifica como crime repercute na esfera do particular de maneira a causar-lhe prejuízos.

A transgressão de uma norma penal enseja duas pretensões: a penal, que visa impor ao autor da infração a aplicação de uma sanção penal, e a civil, impondo a obrigação de reparação dos danos sofridos pela vítima.

Assim, embora independentes as responsabilidades civil e criminal, quando de um ilícito penal resultarem prejuízos de ordem material ou moral para a vítima, restará caracterizado o dever de indenizar.

O prejuízo experimentado pela vítima de um crime é passível de satisfação por meio da chamada ação civil ex delicto, procedimento judicial voltado à recomposição do dano civil causado pelo ilícito penal, posto que os fundamentos do pedido repousam no próprio fato criminoso.

Dispõe o art. 63, CPP que, possui legitimidade para a propositura da ação civil ex delicto, seja na ação de conhecimento ou na execução da sentença penal condenatória, o ofendido, seu representante legal ou seus herdeiros.

Ocorre que, quando qualquer dos legitimados for pobre, na acepção jurídica do termo, ou seja, que não puder prover às despesas do processo sem privar-se dos recursos indispensáveis ao próprio sustento ou de sua família, poderá o Ministério Público, a requerimento dele, propor a execução da sentença condenatória ou a ação civil. É o que estabelece o art. 68, CPP.

Com o advento da Constituição Federal de 1988, atribuindo as funções institucionais do Ministério Público em seu art. 129 e não aludindo a legitimidade para a propositura da ação civil ex delicto e, considerando ainda a criação da Defensoria Pública em seu art. 134, passou-se a questionar a legitimidade ativa do Ministério Público neste mister de substituto processual previsto no art. 68 do CPP.

Portanto, o presente artigo tem por objetivo debater a legitimidade ativa do Ministério Público para a propositura da ação civil ex delicto, tendo em vista a importância de assegurar aos necessitados a reparação dos danos sofridos em decorrência de ilícitos penais, bem como à quem incumbirá de representa-los, posto que a CF/88 atribuiu à Defensoria Pública a orientação jurídica e a defesa, em todos os graus, daqueles. 


\section{METODOLOGIA}

Este estudo desenvolveu-se através do levantamento de bibliografias, leitura e fichamento.

Partindo-se da hipótese levantada e dos dados coletados, estes foram confrontados, interpretados e discutidos por meio do método dedutivo.

\section{DA AÇÃO CIVIL EX DELICTO}

Nos dizeres de Bonfim (2014, p. 256), ação civil ex delicto "é a ação proposta no juízo civil pelo ofendido, seu representante legal ou seus herdeiros para obter a reparação do dano provocado pela infração penal".

Existem dois tipos de ação civil ex delicto para ressarcimento dos danos causados pelo crime: a ação de execução da sentença penal condenatória, a qual equivale a um título executivo judicial; e a ação civil de conhecimento, independente da ação penal, em que o ofendido ingressa desde logo no juízo cível buscando a obtenção da reparação dos danos.

Greco Filho (2013) explica que a ação civil de conhecimento pode ser proposta desde o fato e independente de instrução de procedimento penal, podendo ser ajuizada contra o agente ou contra terceiro responsável, ou ambos, sempre no juízo cível, ao passo que, a sentença penal condenatória transitada em julgado é título executivo judicial e, depois de liquidada no juízo cível, ali será executada.

Cumpre destacar que nesta última hipótese, a execução somente poderá ser proposta contra o réu da ação penal e nunca contra terceiros, tendo em vista que, por não fazer parte do processo penal, contra este não poderá ser formado título judicial sem o devido processo legal.

Conforme verberado alhures, possui legitimidade para a propositura da ação civil ex delicto, o ofendido, seu representante legal ou seus herdeiros. Mas, quando qualquer dos legitimados for pobre, poderá o Ministério Público, a requerimento dele, propor a execução da sentença penal condenatória ou a ação civil de conhecimento.

Logo, para que o Ministério Público atue como substituto processual na propositura da ação civil ex delicto, tem-se como requisitos que a vítima seja pobre, e que haja requerimento desta ao representante do parquet.

No que tange à legitimidade do MP, Greco Filho (2013, p. 151) diz que "trata-se de uma legitimidade extraordinária concorrente, atuando, no caso, o Ministério Público como substituto processual".

Para Magno (2013) não só o MP, mas como maior razão a Defensoria Pública ostentam a legitimidade para ingressar com ação em benefício de desassistido quando tratar-se da ação de 
execução da sentença penal condenatória, pois ainda segundo o autor no caso de ação civil de conhecimento, o MP só poderá ingressar com a ação civil nas hipóteses em que na localidade ainda não houver estrutura da Defensoria Pública.

\section{POSICIONAMENTOS PRÓ E CONTRA A LEGITIMIDADE DO MINISTÉRIO PÚBLICO NAS AÇÕES CIVIS “EX DELICTO”}

Conforme Jesus (2014), no que tange à legitimidade do Ministério Público prevista no art. 68, CPP, há duas posições acerca do assunto: numa primeira posição o dispositivo não foi recepcionado pela $\mathrm{CF} / 88$, tendo em vista que o parquet deve zelar pela defesa dos interesses sociais e individuais indisponíveis e que, a reparação dos danos ex delicto tem natureza estritamente individual e disponível. Noutra posição, o dispositivo continua válido, mantendo-se a legitimidade ativa, pois a norma se mostra compatível com o perfil constitucional atribuído ao Ministério Público.

O grande questionamento, entretanto, acerca da possível não recepção do dispositivo infraconstitucional que prevê a legitimação do MP para a propositura da ação civil ex delicto, paira sobre a criação da figura da Defensoria Pública pela CF/88 em seu art. 134, incumbindo-Ihe a orientação jurídica e a defesa, em todos os graus, dos direitos individuais e coletivos, aos necessitados.

Outro argumento que esbarra em legitimar o MP de tal mister seria que, o art. 129, CF, que prevê as atribuições desta instituição, não aludiu à legitimidade para a propositura de ação civil ex delicto, e que tal omissão seria proposital, no sentido de que a legitimidade seria transferida à Defensoria Pública. (BONFIM, 2014)

Assim, com a instalação das Defensorias Públicas, extinta estaria a legitimidade do MP prevista no art. 68, CPP, ainda que pobre fosse o ofendido, conforme verberado por Machado (2014, p. 170):

Todavia, cumpre destacar que esse dispositivo não encontra mais ressonância na nova ordem constitucional, e está mesmo invalidado pala CF, pois o art. 127 estabelece a legitimidade do Ministério Público apenas para a defesa da ordem jurídica, do regime democrático e dos interesses sociais e individuais indisponíveis, excluindo qualquer possibilidade de esse órgão atuar na defesa de interesse individual disponível, como é o caso da reparação de danos ex delicto. 
Portanto, apenas a Defensoria Pública, por imposição constitucional, é que teria a atribuição de prestar orientação jurídica e defesa dos necessitados, promovendo a execução da sentença condenatória ou ação civil de conhecimento.

Neste mesmo sentido Oliveira (2014, p. 197) salienta que "a razão de ser da legitimação do Ministério Público (pobreza do titular da ação civil) evidentemente deixou de existir".

Tourinho Filho (2012) argumenta que a criação da Defensoria Pública pela CF/88 não recepcionou a norma do art. 68, CPP, salvo nos Estados em que ainda não organizaram a Defensoria Pública. Pontua que trata-se de uma progressiva inconstitucionalidade do artigo em comento, explicando que onde for surgindo a figura do Defensor Público, cessará para o representante do parquet a legitimidade conferida.

O Supremo Tribunal Federal tem se posicionado sobre a legitimidade do MP prevista no art. 68, CPP sob o argumento de que, a CF/88 transferiu-a para a Defensoria Pública, porém, aonde esta ainda não for implementada, nos moldes do art. 134 da Carta Política e da LC 80/94, não há que se falar em transferência constitucional da atribuições. Logo, deve o art. 68, CPP, que legitima o Parquet para promover tal pleito indenizatório, ser considerado ainda vigente. (NUCCl, 2014)

Magno (2012) explica que o STF entendeu que os dispositivos que legitimam o MP padecem de inconstitucionalidade progressiva, na medida em que perderão sua eficácia com a organização da Defensoria Pública nas diversas localidades pois, onde estas forem sendo estabelecidas, o MP irá perdendo progressivamente a legitimidade, só podendo entrar com a ação civil ex delicto nos locais que ainda não houverem sido implantadas as Defensorias.

Inconstitucionalidade progressiva são situações constitucionais imperfeitas que se situam entre a constitucionalidade plena e a inconstitucionalidade absoluta, nas quais as circunstâncias fáticas vigentes naquele momento justificam a manutenção da norma dentro do ordenamento jurídico.

Entretanto, Bonfim (2014, p. 266) bem relata a situação das Defensorias Públicas no Brasil:

De fato, em muitos locais simplesmente não há Defensoria, e, mesmo quando elas existem, muitas vezes não contam com número de defensores suficiente para atender à demanda da população. Assim, a interpretação crua da Constituição acabaria por prejudicar justamente aqueles que necessitam da assistência que a própria Lei Magna visou garantir.

Deve se observar que, a Defensoria Pública só pode se considerar existente, onde e quando organizada, de direito e de fato, nos moldes do art. 134, CF e de lei complementar por ela ordenada. 
Levando-se em conta o posicionamento do STF, Demercian e Maluly (2014) sustentam que, como o cidadão não pode ficar sem o amparo jurídico do Estado, mantém-se a legitimidade do MP para propor a ação civil ex delicto, enquanto não implementada esta substituição.

Mazzilli (1998, p. 24), ao explicar sobre o art. 22, XIII, da LC no 40/81 que impõe aos membros do MP o dever de prestar assistência judiciária aos necessitados, onde não houver órgão próprio, comenta que:

Este dispositivo foi editado antes da criação, em sede constitucional, das Defensorias Públicas, destinadas à orientação jurídica e à defesa dos necessitados, em todos os graus. Assim, desde que criadas e em funcionamento nos Estados, a elas em regra devem caber os misteres da assistência judiciária. Contudo, a Constituição não Ihes deu exclusividade neste mister. Assim, deve ser entendido que, ainda que haja Defensoria Pública destinada ao atendimento, se seus órgãos efetivamente não derem vazão aos casos de acesso à Justiça, a hipótese pode equiparar-se à de inexistência de canais de acesso. Nesta hipótese, somos de parecer que se admita constitucionalmente a prestação de assistência judiciária pelo Ministério Público, num sistema alternativo, embora complementar.

Logo, considerando ainda que compete ao MP exercer outras funções que lhe forem conferidas, desde que compatíveis com sua finalidade, conforme dispõe o art. 129, IX, CF, é plenamente compatível a legitimidade ativa do Ministério Público conferida no art. 68, CPP com seu perfil constitucional atribuído, pois não se pode olvidar que a pobreza é um interesse social, ainda mais diante da abrangência em nosso país.

Portanto, tendo em vista que ao MP Ihe é incumbido a defesa dos interesses sociais - art. 127, CF, sua legitimidade ativa prevista no art. 68, CPP deve ser reconhecida.

\section{CONCLUSÃO}

A ideia de indenizar o dano proveniente de um ilícito penal tem evoluído de simples efeito secundário da sentença condenatória para a natureza de sanção ao lado da pena, como fruto de uma específica política criminal de colaborar na realização das finalidades das sanções penais de caráter preventivo.

Sempre no espírito de preservar os direitos dos hipossuficientes, o Estado busca garantir o acesso dos necessitados à justiça, pois o cidadão carente não pode ficar sem amparo jurídico do Estado. Assim, o legislador constituinte vislumbrou a figura da Defensoria Pública, instituição essencial à função jurisdicional do Estado para prestar orientação jurídica e a defesa dos necessitados. 
Diante da omissão de diversos Estados, e também da União, no encargo constitucional de instituir e organizar as respectivas Defensorias, ou seja, até que se implemente essa condição de viabilização da cogitada transferência constitucional de atribuições, deve o art. 68, CPP ser considerado ainda vigente, ao passo que a atuação do Ministério Público restará em caráter subsidiário, até que se viabilize, em cada Estado, a implementação da Defensoria Pública, posto tratar-se de um progressiva inconstitucionalidade.

\section{REFERÊNCIAS}

BRASIL. Código de Processo Penal. Decreto-Lei no 3.689, de 3 de outubro de 1941. Disponível em: <http://www.planalto.gov.br/ccivil_03/decreto-lei/Del3689.htm>. Acesso em: 11 ago. 2015.

BRASIL. Constituição (1988). Constituição da República Federativa do Brasil. Brasília: Senado Federal, 1988.

BONFIM, E. M. Curso de processo penal. 9. ed. São Paulo: Saraiva, 2014.

DEMERCIAN, P. H.; MALULY, J. A. Curso de processo penal. 9. ed. Rio de Janeiro: Forense, 2014.

GRECO FILHO, V. Manual de processo penal. 10. ed. São Paulo: Saraiva, 2013.

JESUS, D. Código de processo penal anotado. 26. ed. São Paulo: Saraiva, 2014.

MACHADO, A. A. Curso de processo penal. 6. ed. São Paulo: Atlas, 2014.

MAGNO, L. E. Curso de processo penal didático. São Paulo: Atlas, 2013.

MAZZILLI, H. N. O acesso à justiça e o ministério público. 3. ed. São Paulo, 1998.

NUCCI, G. S. Código de processo penal comentado. 13. ed. Rio de Janeiro: Forense, 2014.

OLIVEIRA, E. P. Curso de processo penal. 18. ed. São Paulo: Atlas, 2014.

TOURINHO FILHO, F. C. Manual de processo penal. 15. ed. São Paulo: Saraiva, 2012. 